\title{
Re-imaging the Environment
}

\author{
Valerie Mace \\ London College of Communication \\ Faculty of Design \\ Elephant and Castle \\ London, SE1 6SB \\ United Kingdom \\ v.mace@/cc.arts.ac.uk
}

\begin{abstract}
This paper represents a study of selected visualisation and investigative methods that facilitate the exploration and expression of human emotions and perceptions within real world environments during the design development stages of a project, repositioning exploration and visualisation in spatial design education. It puts forward an outline for an iterative enquiry around human experiences in order to assess the value of alternative cognitive tools for spatial design students in higher education. Established tools such as orthographic drawings, axonometric projections or scale models equip spatial designers with the consistency they need to investigate and represent physical attributes of space but don't always constitute the best methods to explore the perceived environment, even though it is a key contributing factor to the way we experience our surroundings. It is therefore in the interest of design educators to investigate complementary interpretations that enable students to consciously explore less tangible aspects of design such as emotions and multi-sensorial modalities. Projects developed using tools and techniques ranging from digital 2D and 3D image making, photography, film, animation and performance provide an insight into the possibilities offered by existing visual technologies as dynamic study devices of human experiences and contribute to the generation of alternative processes in spatial design education.
\end{abstract}

Visualisation. Spatial design. Education. Perceptions. Digital image making. Animation. Performance.

\section{INTRODUCTION}

Spatial design practitioners and students are today, able to create sophisticated investigations and expressions of interior and exterior spaces in fully integrated work processes across drawing, model making, digital visualisation and simulations, laser cutting and even 3D printing. Yet, given the high level of sophistication available, the methodologies applied to the tools still present inherent limitations and exist outside the reality of experience, a sentiment echoed by Peter Waters in his paper 'Envisaging the Experiential' (Waters 2011).

Conventional techniques evolved from the formalisation of architecture education in the $19^{\text {th }}$ century, when drawing became its accepted language. In three-dimensional representations, perspective drawing 'became the instrument of architectural thinking' (Pallasmaa 2005, p.26). However, perspective drawing restricts the gaze of the viewer to flat viewpoints, which can't facilitate, as expressed by Jean Piaget, a gradual construction of meanings essential to the perception of our environment (Malnar and
Vodvarka, 2004, p.49). It can only happen as we move through a space.

In the $20^{\text {th }}$ century, Modernist architects favoured a more complex system of axonometric drawings that enabled them to look through and at the entire architectural space, in some ways replicating on paper some of the characteristics of a physical model. Yet, however valuable axonometric drawings are to explore spatial relationships, they still fail to convey sensory stimuli. The necessary use of scale may also contribute to a distortion of information. For example, a ten metre high concrete wall looks deceptively small at scale 1:100 and students may not realise the dominating mass it would produce in reality.

So in many ways, designing on paper using conventional tools and methods can provide challenges for students who are looking for a more phenomenological approach to design, one that incorporates experience and perceptions. Virtual environments appeared for a while to be able to bridge that gap, with walkthrough animations introducing motion into the design process but even 
then, the focus remained primarily on providing a form of depiction rather than a way to develop a spatial awareness built on sensory properties and unique environmental and perceptual conditions. So the projects presented here outline a series of experiments performed to investigate and feature less tangible aspects of design, sensory communication and mental immersion. They explore and express human perceptions and emotions and some of the methods used also borrow from scenography and storytelling.

They are inspired by the writings and theories of Merleau-Ponty (1945), Bachelard (1958), Lefebvre (1974), Gibson (1986), Malnar and Vodvarka (2004), Pallasmaa (2005) and Van Schaik (2008) as well as recently published work by the research collective Urban Interior at RMIT University in Melbourne (2011), Peter Waters (2011), Julie Macdermott et al. (2012) and Ephraim Joris (2012). Working from varying perspectives, they advocate a more thoughtful integration of the physical and the mental in design practices.

This is, by no means, an exhaustive exploration. However, doing this allows for a better understanding of how to integrate the experiential aspects of our environment into the design process and appeal to students varied learning styles. Even spaces that have similar functions will be perceived differently and therefore spatial design students benefit from a reappraisal of the methodologies they apply to available tools, helping them towards augmented insights into the world of perceptions.

\section{ENVIRONMENTAL AWARENESS}

The projects outlined in this paper emphasise the development of a mental space and consider situations that inform our awareness of the environment in a dynamic and affective way as when emotions influence our perceptions.

Moving away from the conception of space as a measure of geometrical abstraction, the focus is on the perceived and experienced environment that surrounds us. 'Every animal is, in some degree at least, a perceiver and a behaver. It is sentient and animate [...]. It is a perceiver of the environment and a behaver in the environment' (Gibson 1986, p.8).

Gibson rejects the classical physics notion of bodies in space and instead speaks of medium, substances and surfaces. For example, air constitutes the medium in which we move and allows the transmission of light and vibrations so we can see and hear, as well as chemical diffusions so we can smell (Gibson 1886, p.16-18). When a person moves across an environment, the information and therefore perceptions vary as what we see, hear or smell also becomes different. We activate and adjust perceptual and sensorial systems in relation to new conditions.

So unlike space, an environment is dynamic and complex. It contains information that triggers and stimulates multi-sensorial perceptions. It surrounds us and changes as we move through it. The purpose of these experiments is to explore accessible creative digital tools and techniques students can learn and apply, to immerse themselves in the sensory stimulations embodied in an environment at the point of initial enquiry and generation. In doing so they are able to project themselves into an alternative world of adjusted perceptual awareness.

\subsection{Exploring mental space}

"Beyond situations that have been experienced, discover situations that have been dreamed"

Gaston Bachelard, The Poetics of Space (1958, p.29)

Perceptual Motion is a short animated film created using a range of time based media techniques. Visualisation tools used include photography, animation, Adobe Photoshop ${ }^{\circledR}$ and Adobe After Effects ${ }^{\circledR}$ (Figure 1 and 2). The narrative explores the link between consciousness and environmental conditions. A suitcase acts as a metaphor for the container of our emotions and a praxinoscope symbolises their dynamic and somewhat unpredictable nature, taking the protagonist from one mental space to another through a door that opens and closes as the praxinoscope rotates.

The film expresses the idea that changes in our environment alter our perceptions and the way we feel. It also reveals different environmental narratives, one positive and tranquil and the other negative and despondent, articulating the concept of a perceptual evolutionary state linked to motion and its relationship with time. This is a personal exploration and therefore bound to subjectivity. What it does however is to encourage a more abstract appreciation of our surroundings linked to perceptions. 


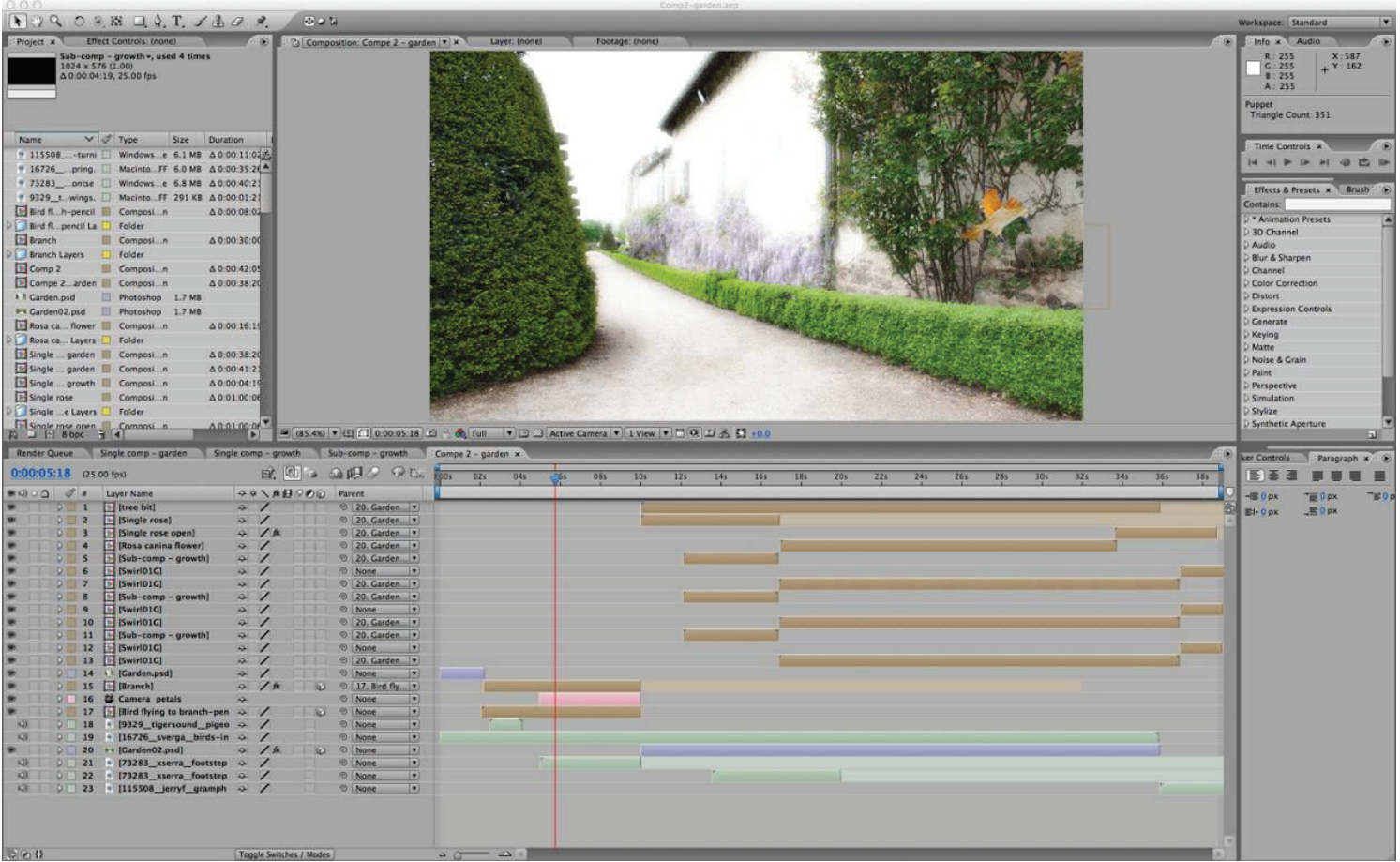

Figure 1: Adobe After Effects screenshot showing the organisation of photographs, animations and sounds used to create the sequence of the positive mental space. The animated bird was drawn frame by frame in Photoshop using a technique called Rotoscoping

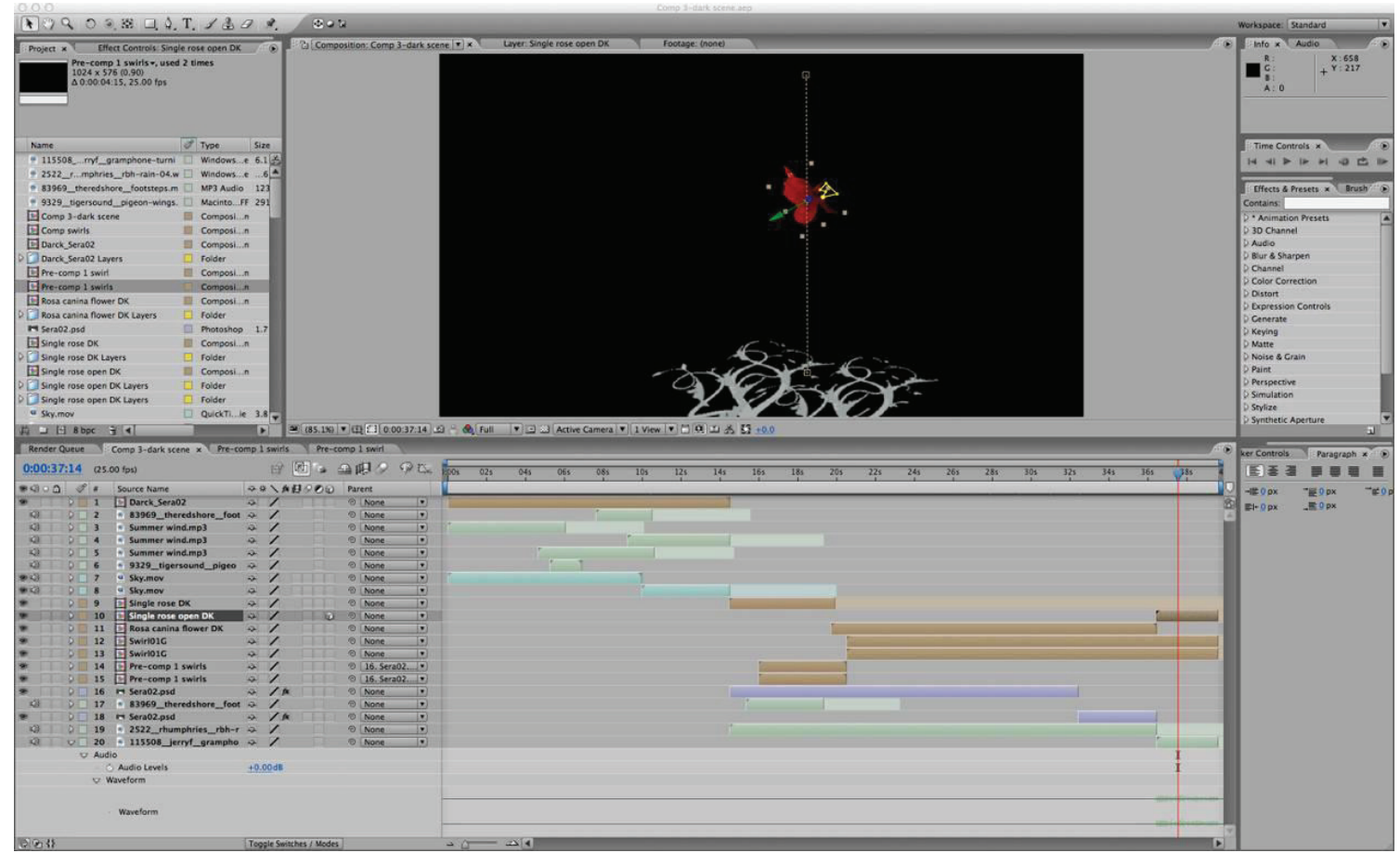

Figure 2: Adobe After Effects screenshot showing the organisation of photographs, animations and sounds used to create the sequence of the negative mental space. The flower fully opens from a bud before falling to the ground. It was drawn frame by frame in Photoshop using a technique called Rotoscoping. The vines on the ground slowly grow towards the background. They were drawn in Adobe Illustrator and each frame created in Photoshop 


\subsection{Exhibition as theatre}

"We need historians, novelists or film makers to bring the spaces of the past to life in the light of the mental space of those who commissioned, designed and made them."

Leon Van Schaik, Spatial Intelligence (2008, p.16)

Conventional case studies usually consist of a report, a format not always suited to expressive experiential accounts, so a case study of Medicine Now, a permanent exhibition on biomedical science at the Wellcome Collection in London Euston, was instead defined as a staged environment in four acts.

\section{Act 1: The Stage \\ Act 2: The Script \\ Act 3: Set Design \\ Act 4: The Play}

Act 1,2 and 3 are presented as a printed visual document but Act 4 is a short film that explores a visitor's experience of the gallery and its content, based on personal interpretations and an evaluation of environmental conditions using drawing (Figure 3) and photography.

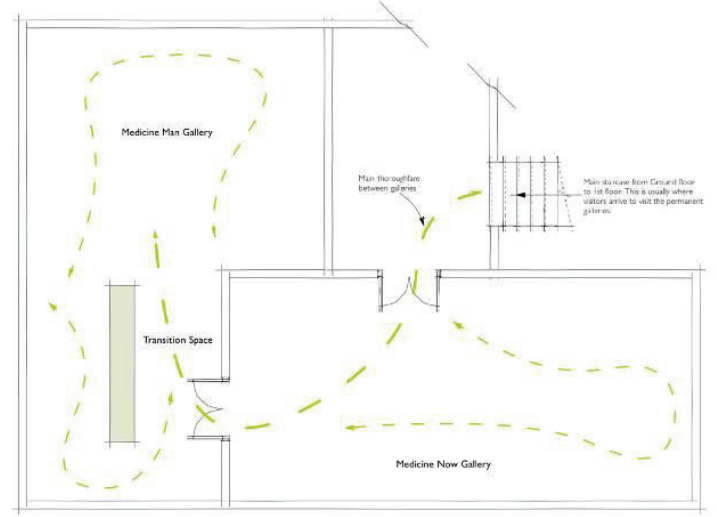

Figure 3: Experiential progression. Floor plan showing the path taken through the galleries on the first floor of the Wellcome Collection building

The scenography of the film functions as a form of exhibition review and differs from traditional written accounts. Expressed in a media not usually used for this purpose by spatial designers, the review becomes perceptual and is able to take us on a journey beyond the limits of the exhibition space. So the method used in this personal interpretation encourages a move beyond the descriptive and analytical towards the reflective and responsive.

In this exhibition visitors are encouraged to participate and even take ownership of some content. So the film format also helps focus the attention on the ladder of participation experienced by the public whereby the encounter feels more like a host-guest relationship rather than a simply passive experience. Visualisation tools used include photography, film, animation, Vectorworks ${ }^{\circledR}$, Adobe Photoshop $\AA$ and Adobe After Effects ${ }^{\circledR}$.

The film is called ' $X$ \& $Y$ ' after the $X$ and $Y$ chromosomes (Figure 4 ) as the Wellcome Trust was instrumental to the development of the Human Genome Project (Figure 5). It explores the concept of scale initiated by the microscopic world of genomes encoded in our DNA and expresses how from this tiny world we discover something bigger than ourselves. The protagonist, a drop of blood, takes us on a journey from the micro to the macro, providing an insight into who we are and how we perceive the world around us. The film is set within a red and white environment as a direct reference to the Wellcome Collection Medicine Now exhibition, while quadratic forms represent the scientific quest to rationalise the unknown.

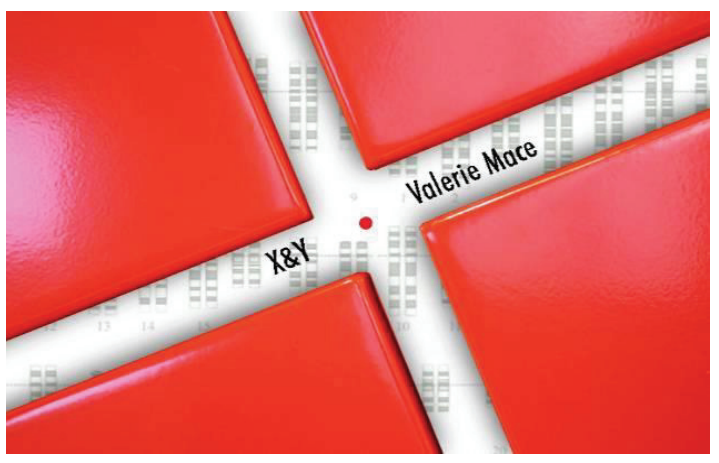

Figure 4: Design for the film title sequence. The panels open diagonally to reveal the title and background

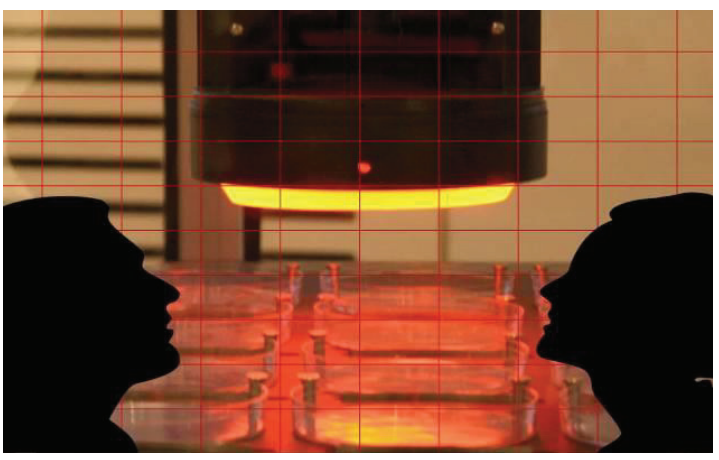

Figure 5: Film frame. Graphic overlay on photograph

\subsection{Performing the environment}

"Architecture is not simply about space and form, but also about event, action, and what happens in space."

Bernard Tschumi, Manhattan Transcripts (1976-1981)

This third project investigates the creation of an embodied experience within a real space, positioning the body in terms of sensing and creating through performance. It relates to the 
concept of synaethetics as defined by $\mathrm{Dr}$ Rosie Klich from the University of Kent at a recent symposium on Immersive Theatre Experiences.

Every spatial design project starts with a conscious investigation of the space, often achieved through site survey, using film, photography and painstakingly recorded measurements on floor plans and elevation drawings. This project approaches the investigation from a different perspective, that of the sensory immersion, the performance. It meets some of the exploratory aspirations of a project described by Ephraim Joris in his paper 'The Interior: between research and practice' but Joris's students benefitted from dance training and choreographed their interpretation accordingly while the method here is much more visceral and considers a more instinctive approach to experiencing an environment.

The site is a small empty room in an abandoned public baths building in Poplar, East London. The room opens up onto the street on one side and onto the main swimming pool, now empty, on the other. Although the interior environment of the building has been neglected for many years and has suffered substantial damage, the site visit revealed a building once teeming with life and the inherent beauty of its Art Deco style hidden by layers of time. From a perceptual perspective, it was like being transported back in time into an imagined environment while being conscious of the present and therefore, feeling the tensions of the duality of time. While exploring the building, I also experienced sound distortions reverberating across the darkness of the corridors and staircases. For a brief moment, I lost sight of the group I was with and could not locate their position with accuracy, as the sound they were making seemed to come from different directions at once.

Back in the studio, the stage was set for a one minute performance of four recurring sequences around the theme of 'The Waiting Room'. One of the elevations of the room was projected onto the wall of the studio and the rest of the interior space was marked out on the floor with masking tape. Three cameras were running, one for the foreground, one for the middleground and another for the background.

Inspired by Freud's essay on the Uncanny, I chose to perform the feeling of loss, duality and the uncanny emerging from the destructive layers of time felt when I visited the site and the momentary confusion that resulted from the sound of people's voices reverberating across the building's surfaces. The room, represented by a figure sitting on a chair (waiting), inhabits its former reality, now a world of stillness and silence. As people speak when they enter the room (in the present time), they create vibrations, which produce energy waves that alter the medium, substances and surfaces, not only across the environment but also time. The room can now hear voices and tries to locate the sounds vibrating across the environment but it can't, (Figure 6 and 7) and people, in their own reality can see the decay and rubble while never experiencing the environment as it was originally intended. When they leave, all is quiet again and the room goes back to its waiting position.

Movement is activated by the emission of sound, a recording of people talking as they enter the room. The movement through the environment is fast but hesitant because it is impossible to locate the source of the sound and incorporates swift $360^{\circ}$ turns to change direction and emphasise the feeling of confusion. When the sound stops, the movement slows down and lacks clear direction.

As well as being filmed, the performance is also recorded as a series of diagrammatic analytical drawings showing the sequence of movement across the floor space (Figure 8) and elevations (Figure 9), bridging the gap between the emotional and the physical, between performance and drawing. Visualisation tools used include photography, film, Vectorworks ${ }^{\circledR}$ and Adobe Photoshop®.

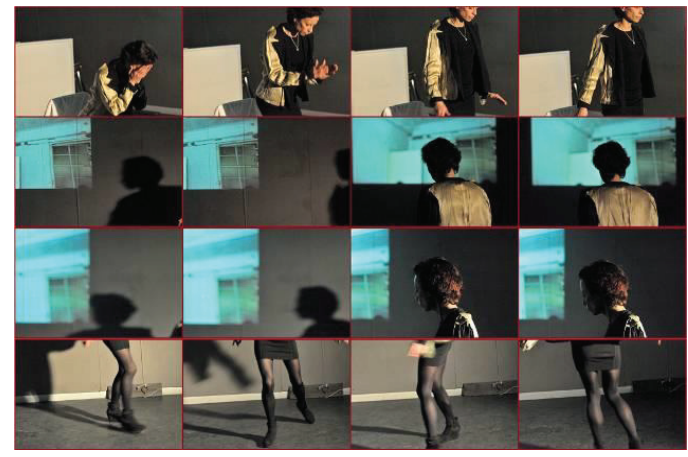

Figure 6: Frames from the performance filmed from the foreground perspective

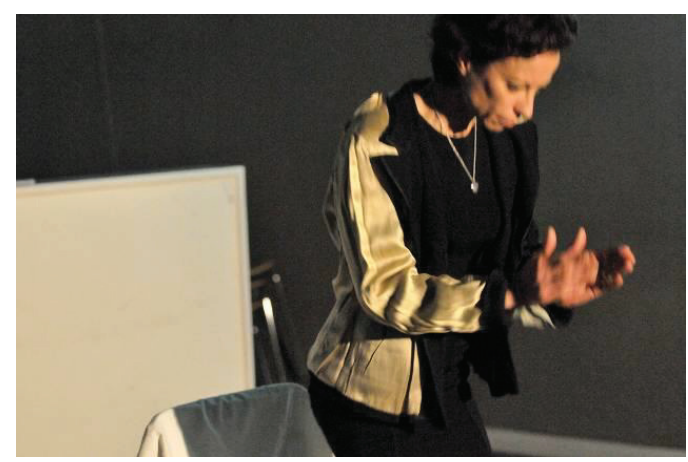

Figure 7: Performing the environment 


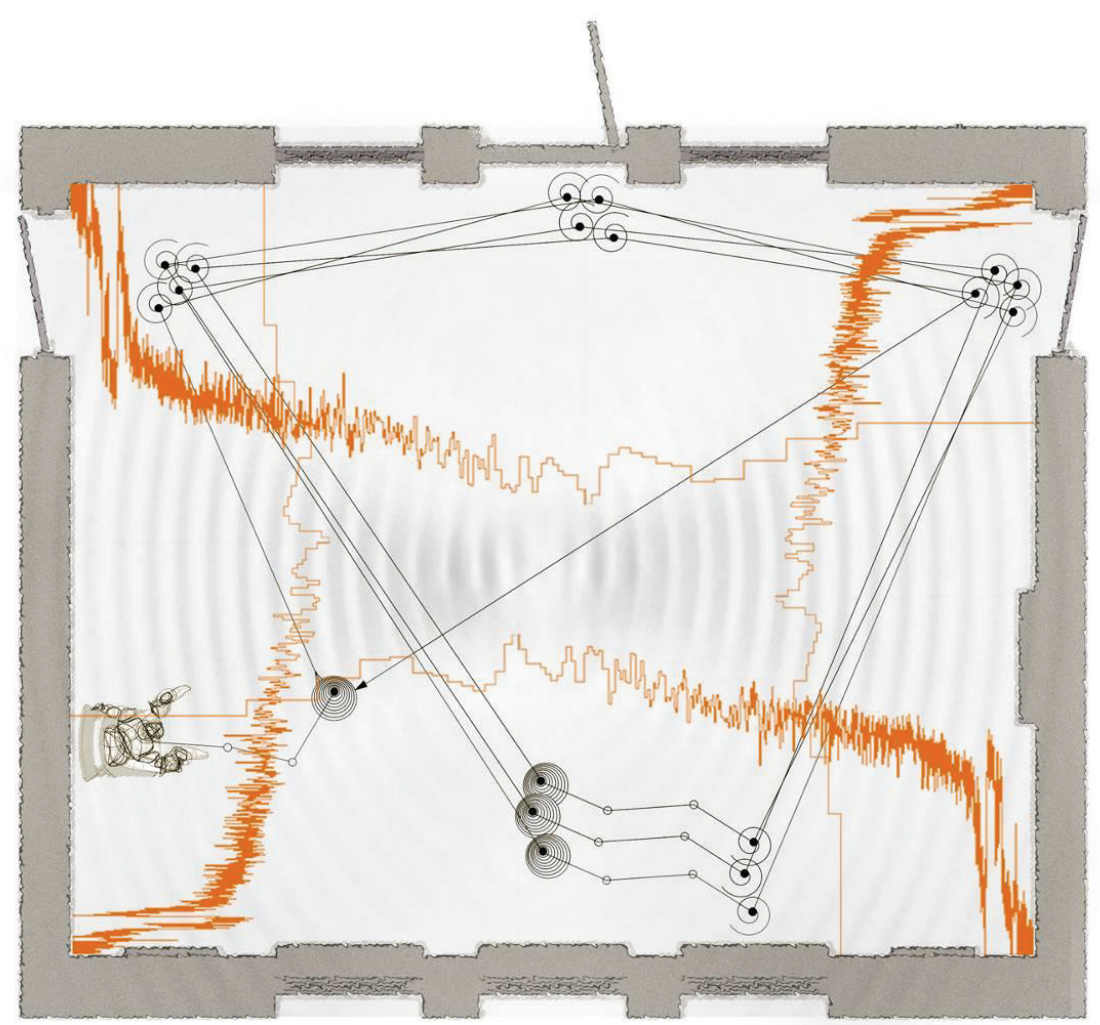

Figure 8: Diagrammatic floor plan mapping the movement sequences and sound distortions. The plan and paths were drawn to scale in Vectorworks ${ }^{\circledR}$ and the sound distortions graphics added in Photoshop ${ }^{\circledR}$

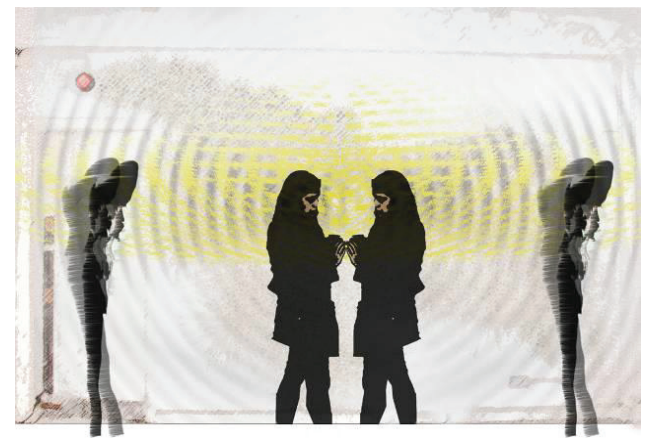

Figure 9: Elevation drawing illustrating a scene from the performance. The drawing also shows the sound scattering across the room and creating distortions across its surfaces

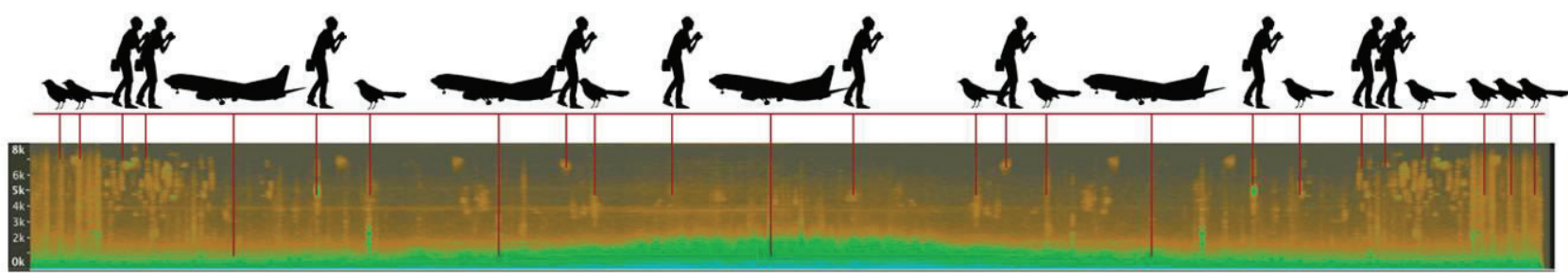

Figure 10: Visual analysis of the sound wave using a spectrogram. The horizontal data corresponds to time and the vertical data to frequency. For the purpose of the study the recording time was edited and mirrored. This spectrogram shows the higher frequency sound of the birds at the top and the lower frequency sound of the plane at the bottom. Also visible on the sound wave below the spectrogram, the sound becomes louder as the plane passes directly above and the volume decreases as the plane moves away 


\subsection{Visualising the invisible}

"A third characteristic of air or water is that it transmits vibrations or pressure waves outward from a mechanical event, a source of sound waves. It thus makes possible hearing what we call the sound; more exactly it permits listening to the vibratory event."

\section{J. J. Gibson, The Ecological Approach to Visual} Perception (1986, p.17)

This project focuses on repositioning our sensory perspective by isolating and visualising sound using a spectrogram and photographic manipulation of the environment. Sounds are emitted at different frequencies, vibrations travel through the environmental medium and are reflected by its surfaces, creating distortions. It is therefore possible to visualise the site as it is disrupted by the sounds passing through its environment like a snapshot capturing pressure waves and distortions.

The project starts with a survey of the medium and substances within the site - wood, leaves, grass, air, bricks - followed by an analysis of the sound recorded on site. The sound wave and spectrogram created in Audacity ${ }^{\circledR}$ illustrate the duration and frequency of an actual recording made on the site. The recording includes the sounds of birds, a plane passing above and the sounds I made while walking through the site and taking photographs. The sounds are referenced by corresponding symbols on the spectrogram (Figure 10).

The analysis is then transposed into a visual representation created in Adobe Photoshop ${ }^{\circledR}$. The image expresses the vibrations and wave-like distortions on the medium and surfaces of the site in an attempt to make the invisible visible (Figure 11 and 12). Producing an environmental image that submerges the perceptual systems of the designer during its making helps enrich awareness of the auditory sensory system.

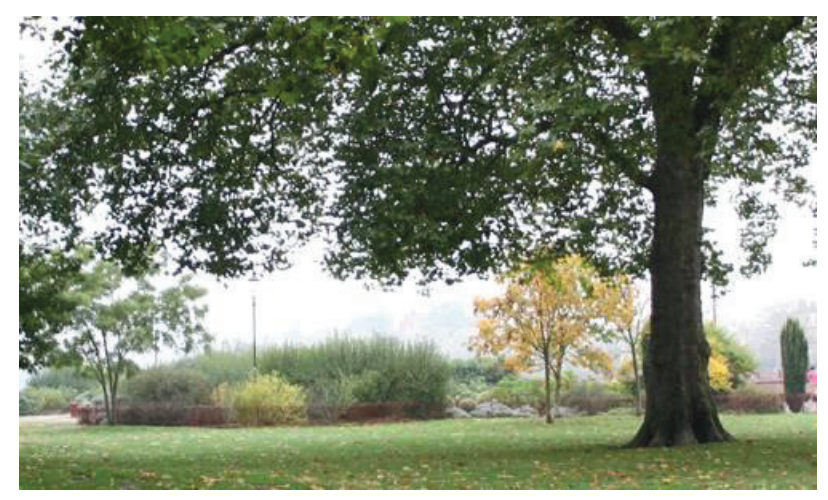

Figure 11: Close up view of the original site prior to manipulation. The ground is perfectly flat and the environment calm and still

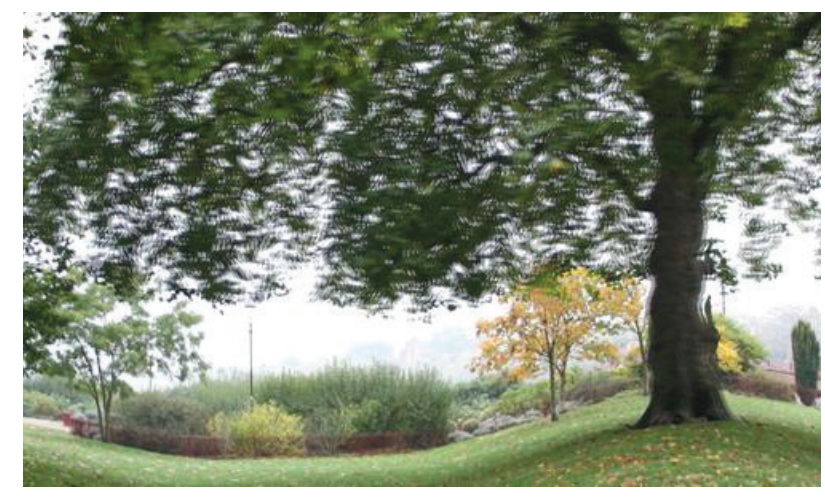

Figure 12: Close up view of the visual representation showing the distortions created by the sounds of the plane and bird across the substances of the tree trunk, leaves and ground

\section{CONCLUSION}

These four experimental projects, with different yet complementary outcomes, underline the potential of existing and readily available digital visualisation tools to facilitate the exploration of experiential and sensory stimulations in our environment. The first project expresses our inability to fully control mental space, a step towards the recognition of the complexity of emotions. The second provides a media based reflective account of an exhibition, taking the viewer on a journey through mental space. The third allows the designer to become the environment and in doing so incorporates the notion of empathy into the design process. The fourth facilitates the comprehension of the auditory sensory system by making invisible sound vibrations appear across an environment. All four acknowledge the importance of experience in spatial design today as, to paraphrase Dr Rosie Klich, 'experience is the commodity of our age.'

The techniques employed, digital drawing and image manipulation tools such as Vectorworks ${ }^{\circledR}$ and Adobe Photoshop $\AA$, are already commonly used in spatial design. Combined with film and animation techniques they provide a critical and engaging alternative to conventional spatial exploration. The focus isn't for students to become professional animators, film makers or even actors, but to expand their opportunities for uncovering aspects of the environments they study or design that are often only superficially considered during the development stages of a project. The objective is to help them better understand perceptual characteristics in the built environment and their impact on the people using them in order to provide better experiences. So the tools and methods were chosen specifically for their availability to students in spatial design with an opportunity to reconfigure existing techniques to suit new methodologies while allowing sufficient time to learn new techniques within the limited timescale of the 
curriculum. Further research in this area will explore ways to incorporate a wider gamut of human experiences into spatial design practice and create tools that facilitate further study and application of processes.

\section{ACKNOWLEDGEMENTS}

I carried out the work presented in this paper in 2012 while a student on the MA Interior Design at the University of Westminster. I'm very grateful to the Course Director, Dusan Decermic, for giving me this opportunity to discover new possibilities, pushing the boundaries of my knowledge and existing practice in such an enjoyable and rewarding way.

\section{REFERENCES}

\section{Books}

Interior Forum Scotland (2011) Interior Tools, Interior Tactics. Debates in interior theory and practice. Libri Publishing, Faringdon. Waters P., Envisaging the experiential p.67

Roger, P. (ed.) (2012) Interior Education Futures. Contemporary Insights. Libri Publishing, Faringdon. Joris E., The Interior: between research and practice. p.59. Macdermott J. et al., Emotion, emotion, emotion. The Spirit of being human. p.75

Merleau-Ponty, M. (ed.) (2012) Phenomenology of Perception Routledge, New York.

Gibson, J.J. (1986) The Ecological Approach to Visual Perception Psychology Press, Hove.
Bachelard, G., (1958) The Poetics of Space Orion Press, New-York.

Pallasmaa, J. (2005) The Eyes of the Skin. Architecture and the Senses. John Wiley and Sons, Chichester.

Malnar, M.J. and Vodvarka, F. (2004) Sensory Design University of Minnesota Press, Minneapolis

Van Schaik, L. (2008) Spatial Intelligence. New Futures for Architecture. AD Primer. John Wiley and Sons, Chichester.

Lefebvre, H. (ed.) (1991) The Production of Space. Blackwell Publishing, Oxford.

Urban Hinkel R. (ed.) (2011) Urban Interior informal explorations, interventions and occupations. Germany: Spurbuchverlag (Urban Interior research collective, School of Architecture and Design, RMIT University, Melbourne, Australia).

\section{Symposium}

Frieze, J., Klitch, R., Vanhoutte, K., and Nelson R. (2013) Immersive Theatre Experiences. The Royal Central School of Speech and Drama, London, 12 February 2013.

http://www.cssd.ac.uk/events/researchevents/immersive-theatre-experiences (retrieved 23 February 2013)

\section{Internet resource}

Bernard Tschumi, Manhattan Transcript. http://www.tschumi.com/projects/18/ (retrieved 25 February 2013) 